\title{
Prevalence of Cholesterol Treatment Eligibility and Medication Use Among Adults - United States, 2005-2012
}

\author{
Carla Mercado, $\mathrm{PhD}^{1}$; Ariadne K. DeSimone ${ }^{2,3}$; Erika Odom, $\mathrm{PhD}^{1}$; Cathleen Gillespie, MS ${ }^{1}$; Carma Ayala, $\mathrm{PhD}^{1}$; Fleetwood Loustalot, PhD ${ }^{1}$
}

A high blood level of low-density lipoprotein cholesterol (LDL-C) remains a major risk factor for atherosclerotic cardiovascular disease (ASCVD) (1), although data from 2005 through 2012 has shown a decline in high cholesterol (total and LDL cholesterol) along with an increase in the use of cholesterol-lowering medications (2-4). The most recent national guidelines (published in 2013) from the American College of Cardiology and the American Heart Association (ACC/AHA) expand previous recommendations for reducing cholesterol to include lifestyle modifications and medication use as part of complete cholesterol management and to lower risk for ASCVD (5-8). Because changes in cholesterol treatment guidelines might magnify existing disparities in care and medication use, it is important to describe persons currently eligible for treatment and medication use, particularly as more providers implement the 2013 ACC/AHA guidelines. To understand baseline estimates of U.S. adults on or eligible for cholesterol treatment, as well as to identify sex and racial/ethnic disparities, CDC analyzed data from the 2005-2012 National Health and Nutrition Examination Surveys (NHANES). Because the 2013 ACC/AHA guidelines focus on initiation or continuation of cholesterol treatment, adults meeting the guidelines' eligibility criteria as well as adults who were currently taking cholesterollowering medication were assessed as a group. Overall, 36.7\% of U.S. adults or 78.1 million persons aged $\geq 21$ years were on or eligible for cholesterol treatment. Within this group, $55.5 \%$ were currently taking cholesterol-lowering medication, and $46.6 \%$ reported making lifestyle modifications, such as exercising, dietary changes, or controlling their weight, to lower cholesterol; $37.1 \%$ reported making lifestyle modifications and taking medication, and $35.5 \%$ reported doing neither. Among adults on or eligible for cholesterol-lowering medication, the proportion taking cholesterol-lowering medication was higher for women than men and for non-Hispanic whites (whites) than
Mexican-Americans and non-Hispanic blacks (blacks). Further efforts by clinicians and public health practitioners are needed to implement complementary and targeted patient education and disease management programs to reduce sex and racial/ethnic disparities among adults eligible for treatment of cholesterol.

NHANES is an ongoing national survey using a complex, multistage, probability sampling design to measure the health and nutritional status of the noninstitutionalized U.S. population.* Detailed physical examinations, including laboratory measures and interviews, were conducted. Data from four 2-year cycles (2005-2012) were analyzed. Exam response rates ranged from $70 \%$ to $77 \%$ for 22,281 participants aged $\geq 21$ years. Participants were excluded from the analyses if they were pregnant $(n=491)$ or missing a fasting laboratory specimen $(n=13,155)$, or if treatment eligibility could not be determined $(n=273)$. When using survey analyses to address the complex sampling design, fasting sample

*Additional information available at http://www.cdc.gov/nchs/nhanes.htm.

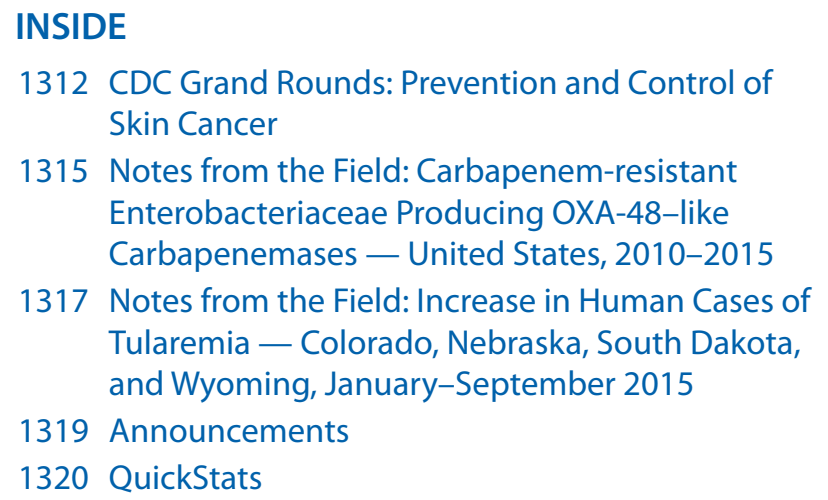

1312 CDC Grand Rounds: Prevention and Control of Skin Cancer

1315 Notes from the Field: Carbapenem-resistant Enterobacteriaceae Producing OXA-48-like Carbapenemases — United States, 2010-2015

1317 Notes from the Field: Increase in Human Cases of Tularemia - Colorado, Nebraska, South Dakota, and Wyoming, January-September 2015

1319 Announcements

1320 QuickStats

Continuing Education examination available at http://www.cdc.gov/mmwr/cme/conted_info.html\#weekly.

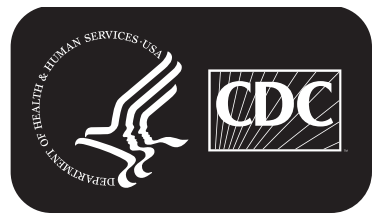

U.S. Department of Health and Human Services Centers for Disease Control and Prevention 
weights were used to account for missing fasting laboratory measures. The final study sample included 8,644 participants. Serum LDL-C levels were calculated based on the Friedewald method (9) using the measured values of total cholesterol, triglycerides, and high-density lipoprotein cholesterol (HDL-C). Adults who were currently taking any cholesterol-lowering medication, or who met eligibility criteria for medication based on the 2013 ACC/AHA guidelines, were defined as meeting current eligibility guidelines for cholesterol treatment.

Current cholesterol-lowering medication use was self-reported from the medical history interview or transcribed from medication bottles recorded in the prescription medication interview. ${ }^{\dagger}$ As outlined by the 2013 ACC/AHA guidelines, persons who should initiate or continue cholesterol-lowering medication included four groups: 1) persons with clinical ASCVD (self-reported history of coronary heart disease, myocardial infarction, stable or unstable angina, or stroke); 2) persons with LDL-C $\geq 190 \mathrm{mg} / \mathrm{dL}$; 3) persons aged 40-75 years with diabetes, LDL-C 70-189 mg/dL, and without clinical ASCVD; and 4) persons aged 40-75 years without clinical ASCVD or diabetes, with LDL-C 70-189 mg/dL, and estimated 10-year ASCVD risk from Pooled Cohort Equation ${ }^{\S} \geq 7.5 \%(5,6)$.

\footnotetext{
${ }^{\dagger}$ Cholesterol-lowering medication considered from medication bottles included bile acid sequestrants, cholesterol absorption inhibitors, HMG-CoA reductase inhibitors (statins), fibric acid derivatives, or combinations/others.

${ }^{\mathfrak{S}}$ Race- and sex-specific equations considering age, total cholesterol, HDL-C, systolic blood pressure, hypertension medication use, smoking status, and diabetes status to calculate 10-year ASCVD risk.
}

Lifestyle modifications were based on affirmative responses when asked whether a "doctor or health professional ever told you to (increase exercise, eat fewer high fat or high cholesterol foods, or control weight to) lower your cholesterol" and self-report that the participant is "now following this advice." Because lifestyle modification questions were not asked for NHANES cycle 2011-2012, estimates for all lifestyle modifications apply to NHANES cycles 2005-2010. All other estimates apply to NHANES cycles 2005-2012.

Analyses were performed using fasting sample weights and adjusted variance estimates to account for complex sampling. Pearson's chi-square test was used to determine significant differences $(\mathrm{p}<0.05)$ across sex and $\mathrm{racial} / \mathrm{ethnic}$ groups. Population counts were estimated using population totals provided from NHANES and averaging the population during the time coinciding with the four NHANES cycles.9

Overall, $36.7 \%$ of U.S. adults or 78.1 million persons aged $\geq 21$ years were on or eligible for cholesterol treatment, among whom $55.5 \%$ were taking cholesterol-lowering medication, and $46.6 \%$ reported making lifestyle modifications to lower cholesterol. There were significant differences in the percentage of men $(40.8 \%)$ and women $(32.9 \% ; \mathrm{p} \leq 0.001)$ on or eligible for treatment as well as among racial/ethnic groups $(24.2 \%$ for Mexican-Americans, 38.4\% for whites, and 39.5\% for blacks; $\mathrm{p}<0.001$ ) (Table 1). Among persons on or eligible for

\footnotetext{
Additional information available at http://www.cdc.gov/nchs/nhanes/response_ rates_cps.htm.
}

The MMWR series of publications is published by the Center for Surveillance, Epidemiology, and Laboratory Services, Centers for Disease Control and Prevention (CDC), U.S. Department of Health and Human Services, Atlanta, GA 30329-4027.

Suggested citation: [Author names; first three, then et al., if more than six.] [Report title]. MMWR Morb Mortal Wkly Rep 2015;64:[inclusive page numbers].

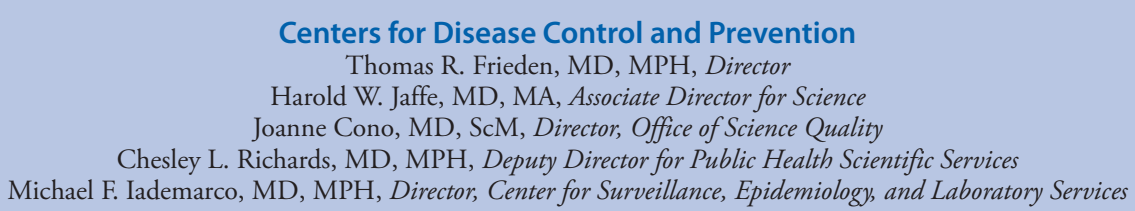

MMWR Editorial and Production Staff (Weekly)

Sonja A. Rasmussen, MD, MS, Editor-in-Chief

Charlotte K. Kent, PhD, MPH, Executive Editor

Jacqueline Gindler, MD, Editor

Teresa F. Rutledge, Managing Editor

Douglas W. Weatherwax, Lead Technical Writer-Editor

Soumya Dunworth, PhD, Teresa M. Hood, MS, Technical Writer-Editors
Martha F. Boyd, Lead Visual Information Specialist

Maureen A. Leahy, Julia C. Martinroe, Stephen R. Spriggs, Moua Yang,

Visual Information Specialists

Quang M. Doan, MBA, Phyllis H. King,

Teresa C. Moreland, Terraye M. Starr,

Information Technology Specialists
MMWR Editorial Board

Timothy F. Jones, MD, Chairman

Matthew L. Boulton, MD, MPH

Virginia A. Caine, MD

Katherine Lyon Daniel, PhD

Jonathan E. Fielding, MD, MPH, MBA

David W. Fleming, MD

\author{
William E. Halperin, MD, DrPH, MPH \\ King K. Holmes, MD, PhD \\ Robin Ikeda, MD, MPH \\ Rima F. Khabbaz, MD \\ Phyllis Meadows, PhD, MSN, RN \\ Jewel Mullen, MD, MPH, MPA
}

Jeff Niederdeppe, $\mathrm{PhD}$

Patricia Quinlisk, MD, MPH

Patrick L. Remington, MD, MPH Carlos Roig, MS, MA

William L. Roper, MD, MPH

William Schaffner, MD 
treatment, there were significant differences in the proportion taking cholesterol-lowering medication between men and women $(52.9 \%$ versus $58.6 \% ; \mathrm{p}=0.010)$ and $\mathrm{racial} / \mathrm{ethnic}$ groups $(58.0 \%$ for whites, $47.1 \%$ for Mexican-Americans, and $46.0 \%$ for blacks; $\mathrm{p}<0.001)$. Significant differences in the proportion of participants on or eligible for cholesterollowering medication were also found among subgroups of age, poverty-to-income ratio, body mass index (BMI), and presence of diabetes or hypertension.

Prevalence of cholesterol-lowering medication use among adults eligible for treatment varied within sex and racial/ethnic subgroups, with the lowest prevalence (5.7\%) among blacks who did not have a routine place for health care and the highest prevalence among persons who reported making lifestyle

TABLE 1. Prevalence of treatment eligibility* among adults aged $\geq 21$ years, and cholesterol-lowering medication use ${ }^{\dagger}$ among adults on or eligible for treatment, by selected characteristics - National Health and Nutrition Examination Survey, United States, 2005-2012

\begin{tabular}{|c|c|c|c|c|c|c|}
\hline \multirow[b]{3}{*}{ Characteristic } & \multicolumn{4}{|c|}{ All } & \multicolumn{2}{|c|}{ Treatment-eligible } \\
\hline & \multicolumn{4}{|c|}{ Prevalence of treatment eligibility* } & \multicolumn{2}{|c|}{ Taking cholesterol-lowering medication ${ }^{\dagger}$} \\
\hline & Sample size & $\%(95 \% \mathrm{Cl})$ & $\begin{array}{l}\text { No. in population } \\
\text { (millions) }\end{array}$ & p-value ${ }^{\S}$ & $\%(95 \% \mathrm{Cl})$ & $p$-value ${ }^{\S}$ \\
\hline$\overline{\text { Total }}$ & 3,737 & $36.7(35.0-38.4)$ & 78.1 & - & $55.5(53.6-57.5)$ & - \\
\hline $\begin{array}{l}\text { Sex } \\
\text { Men } \\
\text { Women }\end{array}$ & $\begin{array}{l}2,051 \\
1,686\end{array}$ & $\begin{array}{l}40.8(38.5-43.1) \\
32.9(30.8-35.1)\end{array}$ & $\begin{array}{l}41.7 \\
36.4\end{array}$ & $<0.001$ & $\begin{array}{l}52.9(50.4-55.5) \\
58.6(55.3-61.7)\end{array}$ & 0.010 \\
\hline $\begin{array}{l}\text { Age group (yrs) } \\
21-39 \\
40-64 \\
\geq 65\end{array}$ & $\begin{array}{r}120 \\
1,850 \\
1,767\end{array}$ & $\begin{array}{r}4.0(3.2-4.9) \\
44.4(41.8-47.0) \\
80.7(78.6-82.7)\end{array}$ & $\begin{array}{r}3.0 \\
43.9 \\
30.3\end{array}$ & $<0.001$ & $\begin{array}{l}41.3(30.7-52.7) \\
51.4(48.3-54.4) \\
62.7(60.0-65.4)\end{array}$ & $<0.001$ \\
\hline $\begin{array}{l}\text { Race/Ethnicity } \\
\text { Mexican-American } \\
\text { Non-Hispanic White } \\
\text { Non-Hispanic Black }\end{array}$ & $\begin{array}{r}507 \\
1,804 \\
844\end{array}$ & $\begin{array}{l}24.2(20.7-28.0) \\
38.4(36.1-40.8) \\
39.5(36.8-42.3)\end{array}$ & $\begin{array}{r}7.5 \\
56.3 \\
9.4\end{array}$ & $<0.001$ & $\begin{array}{l}47.1(42.7-51.5) \\
58.0(55.4-60.6) \\
46.0(41.8-50.3)\end{array}$ & $<0.001$ \\
\hline $\begin{array}{l}\text { Poverty-to-income rat } \\
<100 \% \\
100 \%-299 \% \\
300 \%-499 \% \\
\geq 500 \%\end{array}$ & $\begin{array}{r}668 \\
1,510 \\
629 \\
609\end{array}$ & $\begin{array}{l}34.7(31.4-38.1) \\
38.8(36.2-41.5) \\
33.0(30.4-35.8) \\
36.7(32.9-40.7)\end{array}$ & $\begin{array}{r}9.3 \\
30.6 \\
17.5 \\
20.5\end{array}$ & 0.025 & $\begin{array}{l}46.5(40.5-52.7) \\
54.4(50.8-57.9) \\
57.8(52.7-62.7) \\
58.9(53.3-64.4)\end{array}$ & 0.026 \\
\hline $\begin{array}{l}\text { Education (persons ag } \\
<\text { High school diploma } \\
\text { High school diploma } \\
\text { Some college } \\
\text { ¿College degree }\end{array}$ & $\begin{array}{r}1,214 \\
942 \\
899 \\
668\end{array}$ & $\begin{array}{l}47.1(44.3-49.9) \\
46.1(42.9-49.4) \\
37.4(34.4-40.6) \\
32.0(29.0-35.2)\end{array}$ & $\begin{array}{l}17.8 \\
21.3 \\
20.7 \\
18.3\end{array}$ & $<0.001$ & $\begin{array}{l}54.7(51.1-58.3) \\
56.0(52.3-59.7) \\
54.4(50.0-58.8) \\
57.2(51.1-63.1)\end{array}$ & 0.802 \\
\hline $\begin{array}{l}\text { BMI categories** } \\
\text { Normal } \\
\text { Overweight } \\
\text { Obese }\end{array}$ & $\begin{array}{r}760 \\
1,233 \\
1,649\end{array}$ & $\begin{array}{l}25.4(23.1-27.8) \\
36.8(34.4-39.2) \\
46.7(44.2-49.3)\end{array}$ & $\begin{array}{l}15.8 \\
26.5 \\
35.0\end{array}$ & $<0.001$ & $\begin{array}{l}52.6(47.4-57.7) \\
52.3(48.6-56.0) \\
59.6(56.5-62.5)\end{array}$ & 0.008 \\
\hline $\begin{array}{l}\text { Diabetes }{ }^{t \dagger} \\
\text { Yes } \\
\text { No }\end{array}$ & $\begin{array}{l}1,423 \\
2,309\end{array}$ & $\begin{array}{l}88.3(85.8-90.4) \\
28.9(27.2-30.6)\end{array}$ & $\begin{array}{l}24.5 \\
53.6\end{array}$ & $<0.001$ & $\begin{array}{l}63.1(60.0-66.2) \\
52.0(49.5-54.5)\end{array}$ & $<0.001$ \\
\hline $\begin{array}{l}\text { Hypertension } \$ \S \\
\text { Yes } \\
\text { No }\end{array}$ & $\begin{array}{l}2,411 \\
1,296\end{array}$ & $\begin{array}{l}69.5(66.9-72.0) \\
18.6(17.2-20.2)\end{array}$ & $\begin{array}{l}39.8 \\
38.3\end{array}$ & $<0.001$ & $\begin{array}{l}63.2(60.9-65.5) \\
39.8(36.0-43.8)\end{array}$ & $<0.001$ \\
\hline
\end{tabular}

Abbreviations: $\mathrm{ASCVD}=$ atherosclerotic cardiovascular disease; $\mathrm{BMI}=$ body mass index; $\mathrm{Cl}=$ confidence interval; $\mathrm{LDL}-\mathrm{C}=$ low-density lipoprotein cholesterol.

* Currently taking cholesterol-lowering medication or eligible for cholesterol treatment based on the 2013 American College of Cardiology and the American Heart Association guidelines. Eligibility for cholesterol treatment include persons 1) with clinical ASCVD, 2) with LDL-C $\geq 190 \mathrm{mg} / \mathrm{dL}, 3)$ aged $40-75$ years with diabetes, LDL-C 70-189 mg/dL, and without clinical ASCVD, or 4) aged 40-75 years without clinical ASCVD or diabetes with LDL-C 70-189 mg/dL and estimated 10-year ASCVD risk $\geq 7.5 \%$. (Additional information available at https://circ.ahajournals.org/content/early/2013/11/11/01.cir.0000437738.63853.7a and https://circ.ahajournals. org/content/early/2013/11/11/01.cir.0000437741.48606.98).

† On the basis of 1) responding "yes" to the following questions, "To lower your blood cholesterol, have you ever been told by a doctor or other health professional to take prescribed medicine?" and "Are you now following this advice to take prescribed medicine?" or 2) cholesterol-lowering medication was identified in the prescription medication questionnaire.

$\S \mathrm{p}$-value based on Pearson's chi-square test.

" Ratio of family income to poverty is based on U.S. Department of Health and Human Services poverty guidelines. Additional information available at http://wwwn. cdc.gov/Nchs/Nhanes/2011-2012/DEMO_G.htm\#Analytic_Notes.

** BMl categories: normal $(18.5-<25 \mathrm{~kg} / \mathrm{m} 2)$, overweight $(25-<30 \mathrm{~kg} / \mathrm{m} 2)$, obese $(\geq 30 \mathrm{~kg} / \mathrm{m} 2)$.

t+ Fasting glucose $\geq 126 \mathrm{mg} / \mathrm{dL}, \mathrm{A} 1 \mathrm{C} \geq 6.5$, responded yes to the question "Other than pregnancy, have you ever been told by a doctor that you have diabetes?", or taking medication for diabetes.

$\S \S$ Systolic blood pressure $\geq 140 \mathrm{mmHg}$, diastolic blood pressure $\geq 90 \mathrm{mmHg}$, or taking blood pressure-lowering medication. 
TABLE 2. Prevalence of cholesterol-lowering medication use* among adults aged $\geq 21$ years who are on or eligible for treatment, ${ }^{\dagger}$ by sex and race/ethnicity - National Health and Nutrition Examination Survey, United States, 2005-2012

\begin{tabular}{|c|c|c|c|c|c|c|c|}
\hline \multirow[b]{4}{*}{ Characteristic } & \multicolumn{7}{|c|}{ Cholesterol-lowering medication use among treatment-eligible adults } \\
\hline & \multicolumn{3}{|c|}{ Sex } & \multicolumn{4}{|c|}{ Race/ethnicity } \\
\hline & Men & Women & & Mexican-American & Non-Hispanic white & Non-Hispanic black & \\
\hline & $\%(95 \% \mathrm{Cl})$ & $\%(95 \% \mathrm{Cl})$ & p-value ${ }^{\S}$ & $\%(95 \% \mathrm{Cl})$ & $\%(95 \% \mathrm{Cl})$ & $\%(95 \% \mathrm{Cl})$ & p-value ${ }^{\S}$ \\
\hline \multicolumn{8}{|l|}{ Age group (yrs) } \\
\hline $21-39$ & $44.1(27.9-61.6)$ & $38.2(16.2-66.4)^{9}$ & 0.665 & $48.7(21.5-76.0)$ & $37.5(18.9-56.1)$ & $58.4(34.6-82.2)$ & 0.262 \\
\hline $40-64$ & $47.5(43.5-51.4)$ & $56.9(51.4-62.4)$ & 0.012 & $42.2(36.5-47.9)$ & $55.0(50.7-59.3)$ & $41.2(35.3-47.1)$ & $<0.001$ \\
\hline$\geq 65$ & $63.4(59.0-67.9)$ & $62.1(58.8-65.4)$ & 0.637 & $58.4(47.3-69.6)$ & $63.0(59.7-66.3)$ & $55.6(49.4-61.9)$ & 0.059 \\
\hline \multicolumn{8}{|c|}{ Poverty-to-income ratio** } \\
\hline$<100 \%$ & $38.4(29.3-47.6)$ & $52.5(45.5-59.5)$ & 0.004 & $45.5(37.3-53.8)$ & $47.9(35.4-60.5)$ & $44.1(33.3-54.8)$ & 0.719 \\
\hline $100 \%-299 \%$ & $49.9(45.8-54.0)$ & $58.6(53.4-63.8)$ & 0.010 & $46.5(37.4-55.7)$ & $56.9(51.7-62.1)$ & $45.2(39.6-50.9)$ & 0.001 \\
\hline $300 \%-499 \%$ & $59.0(52.3-65.6)$ & $56.2(48.9-63.4)$ & 0.540 & $60.8(44.8-76.8)$ & $58.0(51.0-65.1)$ & $53.5(41.4-65.6)$ & 0.625 \\
\hline$\geq 500 \%$ & $54.5(46.6-62.4)$ & $67.7(59.6-75.8)$ & 0.026 & $38.9(24.5-53.3)$ & $60.6(53.3-67.9)$ & $46.0(30.9-61.1)$ & 0.016 \\
\hline \multicolumn{8}{|c|}{ Education (persons aged $\geq 25$ yrs) } \\
\hline$<$ High school diploma & $52.0(47.1-56.8)$ & $57.5(52.2-62.8)$ & 0.161 & $43.9(37.6-50.2)$ & $62.4(56.1-68.7)$ & $43.7(35.8-51.6)$ & $<0.001$ \\
\hline High school diploma & $47.3(42.5-52.2)$ & $64.0(59.1-69.0)$ & $<0.001$ & $53.0(36.2-69.8)$ & $57.9(52.6-63.2)$ & $45.6(35.8-55.3)$ & 0.017 \\
\hline Some college & $52.2(44.6-59.8)$ & $57.0(50.6-63.4)$ & 0.368 & $50.8(31.8-69.7)$ & $55.2(49.3-61.0)$ & $47.6(39.6-55.5)$ & 0.171 \\
\hline$\geq$ College degree & $58.7(51.7-65.6)$ & $54.7(44.8-64.6)$ & 0.428 & $55.4(36.0-74.8)$ & $58.5(51.2-65.7)$ & $48.7(35.7-61.7)$ & 0.213 \\
\hline \multicolumn{8}{|l|}{ BMI categories $^{\dagger+}$} \\
\hline Normal & $47.1(40.1-54.2)$ & $58.6(52.1-65.0)$ & 0.011 & $41.4(31.9-51.0)$ & $53.6(45.8-61.3)$ & $35.8(25.5-46.1)$ & 0.003 \\
\hline Overweight & $48.5(43.7-53.3)$ & $58.0(52.6-63.3)$ & 0.010 & $46.4(37.6-55.1)$ & $54.9(50.5-59.4)$ & $39.7(31.3-48.1)$ & $<0.001$ \\
\hline Obese & $59.7(56.0-63.4)$ & $59.4(54.8-64.0)$ & 0.917 & $49.8(42.4-57.2)$ & $62.7(58.4-66.9)$ & $52.7(47.0-58.4)$ & $<0.001$ \\
\hline \multicolumn{8}{|l|}{ Diabetes $\S \S$} \\
\hline Yes & $65.0(61.2-68.8)$ & $61.2(55.7-66.8)$ & 0.316 & $53.5(47.5-59.5)$ & $65.8(60.8-70.8)$ & $58.7(53.0-64.5)$ & 0.002 \\
\hline No & $47.8(44.5-51.2)$ & $57.2(53.1-61.3)$ & 0.002 & $39.8(31.5-48.1)$ & $55.1(52.1-58.0)$ & $36.4(30.6-42.3)$ & $<0.001$ \\
\hline \multicolumn{8}{|l|}{ Hypertension ๆી } \\
\hline Yes & $69.7(66.5-72.9)$ & $65.1(61.2-69.0)$ & 0.072 & $60.7(53.7-67.7)$ & $68.8(65.6-72.1)$ & $58.6(53.6-63.6)$ & $<0.001$ \\
\hline No & $29.9(25.8-34.0)$ & $47.1(41.6-52.6)$ & $<0.001$ & $29.6(21.9-37.3)$ & $41.0(36.3-45.7)$ & $15.9(10.3-21.6)$ & $<0.001$ \\
\hline \multicolumn{8}{|l|}{ History of ASCVD*** } \\
\hline Yes & $71.3(65.6-76.9)$ & $53.4(48.4-58.4)$ & $<0.001$ & $49.2(37.7-60.7)$ & $66.1(60.5-71.7)$ & $51.1(43.0-59.2)$ & $<0.001$ \\
\hline No & $46.4(43.5-49.3)$ & $60.3(56.8-63.8)$ & $<0.001$ & $46.2(41.8-50.6)$ & $54.8(51.7-58.0)$ & $44.2(39.4-48.9)$ & $<0.001$ \\
\hline \multicolumn{8}{|l|}{ Health care coverage ${ }^{t+\dagger}$} \\
\hline Yes & $56.8(54.0-59.6)$ & $61.6(58.3-65.0)$ & 0.041 & $55.5(48.9-62.0)$ & $60.4(57.8-63.1)$ & $49.5(45.8-53.3)$ & $<0.001$ \\
\hline No & $26.0(18.9-33.2)$ & $34.0(26.5-41.5)$ & 0.148 & $32.2(19.9-44.5)$ & $31.5(20.4-42.7)$ & $27.1(16.9-37.3)$ & 0.748 \\
\hline \multicolumn{8}{|c|}{ Health care coverage types $\S$} \\
\hline Medicare & $59.2(51.3-67.2)$ & $60.1(50.6-69.6)$ & 0.859 & $59.4(50.6-68.2)$ & $60.0(50.7-69.3)$ & $53.7(42.9-64.4)$ & 0.516 \\
\hline Private & $55.8(52.1-59.4)$ & $61.7(57.4-65.9)$ & 0.049 & $49.7(41.5-57.9)$ & $59.8(56.7-63.0)$ & $46.8(41.4-52.2)$ & $<0.001$ \\
\hline Public & $59.4(53.1-65.8)$ & $62.6(56.3-68.9)$ & 0.412 & $63.1(46.0-80.3)$ & $63.6(55.5-71.8)$ & $52.3(46.0-58.5)$ & 0.067 \\
\hline \multicolumn{8}{|c|}{ Routine place for health care } \\
\hline Yes & $56.4(53.7-59.0)$ & $60.0(56.9-63.2)$ & 0.103 & $54.3(48.7-59.9)$ & $59.8(57.2-62.4)$ & $49.0(44.6-53.4)$ & $<0.001$ \\
\hline No & $15.7(7.0-24.4)$ & $26.8(16.0-37.7)$ & 0.083 & $17.9(5.6-30.3)^{9}$ & $24.0(13.2-34.8)$ & $5.7(3.4-8.0)$ & 0.044 \\
\hline
\end{tabular}

See table footnotes on next page.

modifications (approximately $80 \%$ for a majority of subgroups) (Table 2). Among adults on or eligible for treatment, prevalence of cholesterol-lowering medication use $(\mathrm{p} \leq 0.001)$ and making lifestyle modifications $(\mathrm{p}=0.001)$ was higher for those with lower LDL-C levels (Figure).

\section{Discussion}

During 2005-2012, based on the 2013 ACC/AHA guidelines, approximately $37 \%$ of U.S. adults were on or eligible for cholesterol-lowering medication. Eligibility for and use of cholesterol-lowering medication differed by sex and race/ ethnicity across various sociodemographic and health-related factors. Among adults who were eligible for treatment, disparities in the proportion taking cholesterol-lowering medication existed among categories of sex, racial/ethnicity, age, poverty-to-income ratio, BMI, and presence of diabetes or hypertension. This report is one of the first to examine sex and racial/ethnic differences in medication use in a nationally representative sample of adults who are eligible for treatment.

Similar to those of previous reports $(7,10)$, these results indicate that approximately half of treatment-eligible adults were taking cholesterol-lowering medication according to the newly released 2013 ACC/AHA guidelines. Furthermore, lower percentages of treatment-eligible Mexican-Americans and blacks were taking cholesterol-lowering medication compared with whites. A majority of persons who reported making lifestyle modifications were also taking cholesterol-lowering medication. Lifestyle modifications, including engaging in 
Morbidity and Mortality Weekly Report

TABLE 2. (Continued) Prevalence of cholesterol-lowering medication use ${ }^{*}$ among adults aged $\geq 21$ years who are on or eligible for treatment, ${ }^{\dagger}$ by sex and race/ethnicity — National Health and Nutrition Examination Survey, United States, 2005-2012

\begin{tabular}{|c|c|c|c|c|c|c|c|}
\hline \multirow[b]{4}{*}{ Characteristic } & \multicolumn{7}{|c|}{ Cholesterol-lowering medication use among treatment-eligible adults } \\
\hline & \multicolumn{3}{|c|}{ Sex } & \multicolumn{4}{|c|}{ Race/ethnicity } \\
\hline & Men & Women & & Mexican-American & Non-Hispanic white & Non-Hispanic black & \\
\hline & $\%(95 \% \mathrm{Cl})$ & $\%(95 \% \mathrm{Cl})$ & p-value ${ }^{\S}$ & $\%(95 \% \mathrm{Cl})$ & $\%(95 \% \mathrm{Cl})$ & $\%(95 \% \mathrm{Cl})$ & p-value ${ }^{\S}$ \\
\hline \multicolumn{8}{|c|}{ No. of times received health care in past $\mathrm{yr}^{* * * *}$} \\
\hline 0 & $7.6(2.5-12.7)^{9}$ & $17.4(4.5-30.3)^{\text {ๆ }}$ & 0.047 & $12.4(4.1-20.8)^{9}$ & $11.6(0.2-23.1)^{9}$ & $6.6(3.7-9.5)$ & 0.638 \\
\hline 1 & $34.2(26.1-42.4)$ & $44.1(33.7-54.6)$ & 0.102 & $28.4(14.6-42.3)$ & $43.1(31.3-54.9)$ & $19.2(6.7-31.7)^{9}$ & 0.002 \\
\hline$\geq 2$ & $62.1(59.2-64.9)$ & $62.6(59.8-65.4)$ & 0.805 & $60.9(54.5-67.2)$ & $63.3(60.8-65.8)$ & $54.5(49.2-59.8)$ & 0.002 \\
\hline Aware of high cholesterol ${ }^{\dagger+t \dagger}$ & $75.1(71.9-78.4)$ & $78.5(75.5-81.6)$ & 0.147 & $75.5(68.5-82.6)$ & $77.7(74.8-80.7)$ & $71.1(67.5-74.8)$ & 0.025 \\
\hline Lifestyle modifications ${ }^{\S \S \S}$ & $79.7(76.1-83.3)$ & $79.2(74.8-83.6)$ & 0.867 & $81.1(73.6-88.5)$ & $80.1(76.1-84.1)$ & $72.1(65.7-78.5)$ & 0.040 \\
\hline Exercising & $81.8(77.6-86.0)$ & $82.9(77.7-88.0)$ & 0.733 & $81.5(74.2-88.9)$ & $83.0(78.0-88.0)$ & 77.5 (71.2-83.8) & 0.012 \\
\hline Diet changes & $80.4(77.1-83.8)$ & $78.9(74.5-83.3)$ & 0.596 & $82.3(72.6-92.0)$ & $80.6(76.8-84.4)$ & $70.4(63.8-76.9)$ & 0.076 \\
\hline Weight control & 80.5 (75.9-85.2) & $83.4(78.8-87.9)$ & 0.403 & $83.0(75.0-90.9)$ & $82.6(77.6-87.6)$ & $73.9(67.0-80.9)$ & 0.195 \\
\hline
\end{tabular}

Abbreviations: $\mathrm{ASCVD}=$ atherosclerotic cardiovascular disease; $\mathrm{BMI}=$ body mass index; $\mathrm{Cl}=$ confidence interval; $\mathrm{LDL}-\mathrm{C}=$ low-density lipoprotein cholesterol.

* On the basis of 1) responding "yes" to the following questions, "To lower your blood cholesterol, have you ever been told by a doctor or other health professional to take prescribed medicine?" and "Are you now following this advice to take prescribed medicine?" or 2) cholesterol-lowering medication was identified in the prescription medication questionnaire.

${ }^{\dagger}$ Currently taking cholesterol-lowering medication or eligible for cholesterol treatment based on the 2013 American College of Cardiology and the American Heart Association guidelines. Eligibility for cholesterol treatment include persons 1) with clinical ASCVD, 2) with LDL-C $\geq 190 \mathrm{mg} / \mathrm{dL}, 3$ ) aged 40-75 years with diabetes, LDL-C 70-189 mg/dL, and without clinical ASCVD, or 4) aged 40-75 years without clinical ASCVD or diabetes with LDL-C 70-189 mg/dL and estimated 10-year ASCVD risk $\geq 7.5 \%$. (Additional information available at https://circ.ahajournals.org/content/early/2013/11/11/01.cir.0000437738.63853.7a and https:// circ.ahajournals.org/content/early/2013/11/11/01.cir.0000437741.48606.98).

$\S$ p-value based on Pearson's chi-square test.

" Estimates statistically unstable with relative standard error $\geq 30 \%$. These estimates should be interpreted with caution.

** Ratio of family income to poverty is based on U.S. Department of Health and Human Services poverty guidelines. Additional information available at http:// wwwn.cdc.gov/Nchs/Nhanes/2011-2012/DEMO_G.htm\#Analytic_Notes.

†† BMI categories: normal $(18.5-<25 \mathrm{~kg} / \mathrm{m} 2)$, overweight $(25-<30 \mathrm{~kg} / \mathrm{m} 2)$, obese ( $\geq 30 \mathrm{~kg} / \mathrm{m} 2)$.

$\S \S$ Fasting glucose $\geq 126 \mathrm{mg} / \mathrm{dL}, \mathrm{A} 1 \mathrm{C} \geq 6.5$, responded yes to the question "Other than pregnancy, have you ever been told by a doctor that you have diabetes?" or taking medication for diabetes.

११ Systolic blood pressure $\geq 140 \mathrm{mmHg}$, diastolic blood pressure $\geq 90 \mathrm{mmHg}$, or taking blood pressure-lowering medication.

*** Self-reported history of coronary heart disease, myocardial infarction, stable or unstable angina, or stroke.

†+† Participants were asked, "Are you covered by health insurance or some other health care plan?"

$\S \S \S$ Health care coverage type reported were Medicare, private insurance, public health insurance (Medicaid, Children's Health Insurance Program, state- or governmentsponsored health plan, or military health plan), or more than one type.

११ๆ On the basis of response to the question, "Is there a place that you usually go when sick or need advice about health?"

**** On the basis of response to the question, "During the past 12 months, how many times have you seen a doctor or other health care professional about your health, not including being hospitalized overnight?"

${ }^{+t+t}$ On the basis of response to the question, "Have you ever been told by a doctor or other health professional that your blood cholesterol level was high?"

$\S \S \S \S$ Each lifestyle modification (exercising, diet changes [less dietary fat], and weight control) was determined by answering "yes" to the following questions, "To lower your blood cholesterol, have you ever been told by a doctor to (increase exercise, eat fewer high fat or high cholesterol foods, or control weight)?" and "Are you now following this advice to (increase exercise, eat fewer high fat or high cholesterol foods, or control weight)?" Questions were not asked in the 2011-2012 National Health and Nutrition Examination Survey cycle, and estimates represent cycles 2005-2010.

regular physical activity, adhering to a heart-healthy diet, and maintaining a healthy weight, are well-known primary and critical components of health promotion and ASCVD risk reduction when implemented before and in combination with cholesterol-lowering medication $(5,8)$. In alignment with incentives offered to health providers in the use of electronic medical records to improve patient care and to promote equitable and high-quality care, clinicians and public health practitioners can use sociodemographic data within their electronic health records to characterize the populations within their practices who are eligible for cholesterol treatment and implement targeted screening, patient education, and disease management programs. In addition, the 2013 ACC/AHA guidelines propose that clinicians monitor therapeutic response to cholesterol-lowering medications and reinforce adherence to both lifestyle regimens and medication at regular intervals (5). Finally, stakeholders should implement evidence-based interventions from the Guide to Community Preventive Services to improve screening and management of cholesterol.**

The findings in this report are subject to at least five limitations. First, the proportion of adults eligible for treatment might be underestimated, because older adults in nursing homes or other institutions, who are more likely to be eligible for cholesterol treatment, are not included in NHANES. Second, estimates for lifestyle modifications only represent data from 2005-2010. Third, although NHANES data collection is standardized, selfreported data are subject to recall bias. Fourth, adults taking

\footnotetext{
** Additional information available at http://www.thecommunityguide.org/cvd/ ROPC.html.
} 
FIGURE. Number* and percentage of adults aged $\geq 21$ years who are on or eligible for cholesterol-lowering treatment, ${ }^{\dagger}$ distribution of LDL-C ${ }^{\S}$ levels, and percentage taking cholesterol-lowering medication," making lifestyle modifications,** or both - National Health and Nutrition Examination Survey, United States, 2005-2012

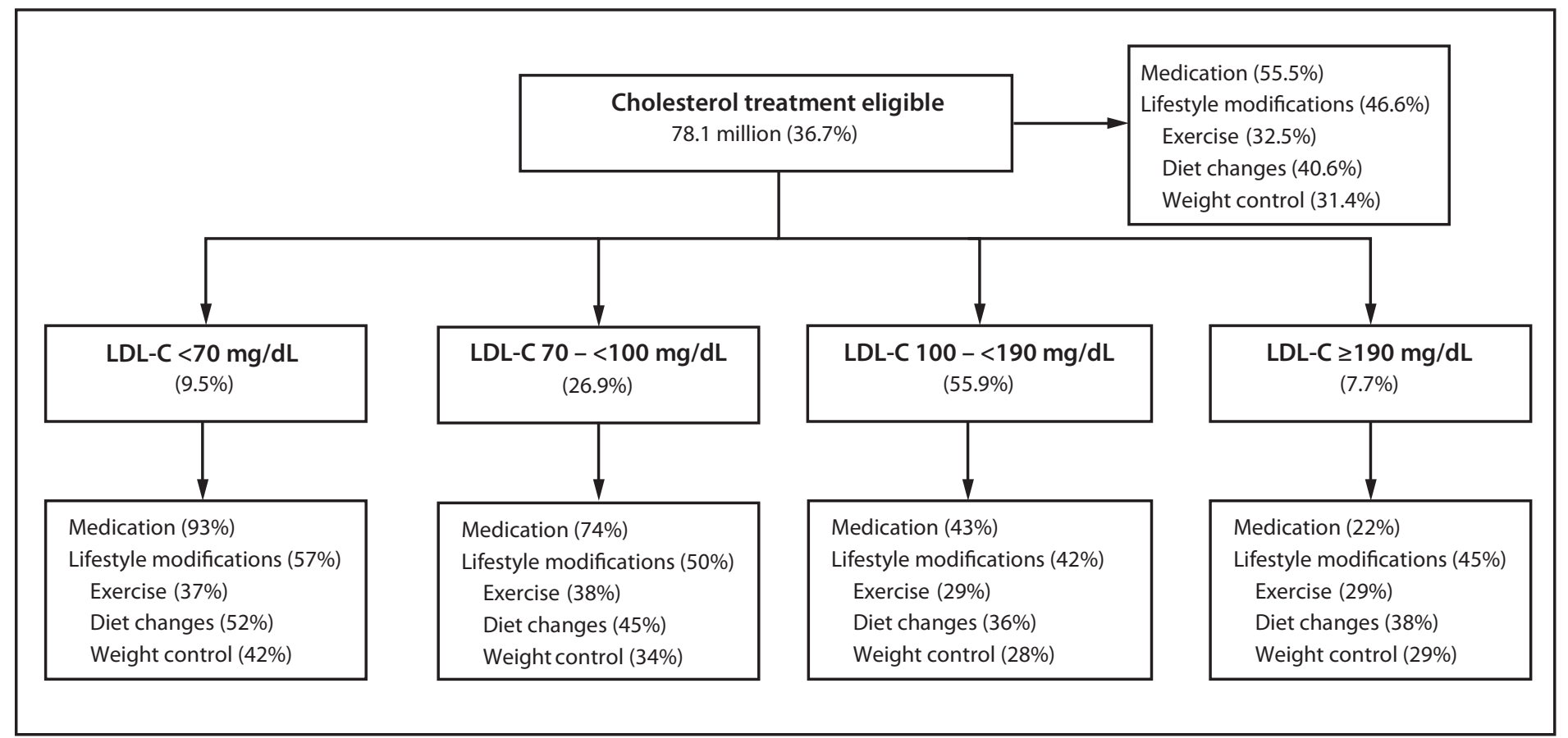

Abbreviations: $\mathrm{ASCVD}=$ atherosclerotic cardiovascular disease; $\mathrm{LDL}-\mathrm{C}=$ low-density lipoprotein cholesterol; NHANES = National Health and Nutrition Examination Survey. * Weighted population count was estimated using Current Population Surveys averaging the population across the four NHANES cycles (2005-2006, 2007-2008, 2009-2010, and 2011-2012).

† Currently taking cholesterol-lowering medication or eligible for cholesterol treatment based on the 2013 American College of Cardiology and the American Heart Association guidelines. Eligibility for cholesterol treatment include persons 1) with clinical ASCVD, 2) with LDL-C $\geq 190 \mathrm{mg} / \mathrm{dL}, 3$ ) aged 40-75 years with diabetes, LDL-C 70-189 mg/dL, and without clinical ASCVD, or 4) aged 40-75 years without clinical ASCVD or diabetes with LDL-C 70-189 mg/dL and estimated 10-year ASCVD risk $\geq 7.5 \%$. (Additional information available at https://circ.ahajournals.org/content/early/2013/11/11/01.cir.0000437738.63853.7a and https://circ.ahajournals.org/ content/early/2013/11/11/01.cir.0000437741.48606.98).

$\S$ Serum LDL-C levels calculated based on Friedewald method (http://www.clinchem.org/content/18/6/499.full.pdf) using measured values of total cholesterol, triglycerides, and high-density lipoprotein cholesterol.

" On the basis of 1) responding "yes" to the following questions, "To lower your blood cholesterol, have you ever been told by a doctor or other health professional to take prescribed medicine?" and "Are you now following this advice to take prescribed medicine?" or 2) cholesterol-lowering medication was identified in the prescription medication questionnaire.

** Each lifestyle modification (exercising, diet changes [less dietary fat], and weight control) was determined by answering yes to the following questions, "To lower your blood cholesterol, have you ever been told by a doctor or other health professional to (increase exercise, eat fewer high fat or high cholesterol foods, or control weight)?" and "Are you now following this advice to (increase exercise, eat fewer high fat or high cholesterol foods, or control weight)?" Questions were not asked in the 2011-2012 NHANES cycle, and estimates represent cycles 2005-2010.

cholesterol-lowering medications were considered to be receiving treatment aligned with the 2013 ACC/AHA guidelines, potentially overestimating prevalence of eligibility and treatment use. Fifth, persons taking medication included any type of cholesterollowering medication and not only statin therapy as recommended by the 2013 ACC/AHA guidelines. However, based solely on the prescription medication file, approximately $88 \%$ of persons taking any cholesterol-lowering medication were taking statins.

Cholesterol treatment for the reduction of ASCVD risk is promoted widely in the United States, including activities such as Healthy People 2020 (11) and the Million Hearts initiative (12). CDC-funded state programs use public health strategies for cardiovascular disease and risk factor management outlined in the Million Hearts initiative, including strategies related to improving clinical management of cholesterol. For example, CDC supports Well-Integrated Screening and Evaluation for Women Across the Nation (WISEWOMAN) ${ }^{\dagger \dagger}$ programs in 20 states and two tribal organizations, and State Public Health Actions to Prevent and Control Diabetes, Heart Disease, Obesity, and Associated Risk Factors and Promote School Health ${ }^{\$ \S}$ grants in all 50 states and the District of Columbia. These include and provide healthy behavior support for populations at risk and provide comprehensive and effective management of primary cardiovascular disease risk factors. Coordinated community and clinical programs are needed to better identify all persons now eligible for cholesterol treatment.

\footnotetext{
†† Additional information available at http://www.cdc.gov/wisewoman.

$\$ \$$ Additional information available at http://www.cdc.gov/dhdsp/programs/ spha/index.htm.
} 


\section{Summary}

What is already known on this topic?

A high blood level of low-density lipoprotein cholesterol $(\mathrm{LDL}-\mathrm{C})$ is a major risk factor for the development of atherosclerotic cardiovascular disease (ASCVD). Lifestyle modification, when implemented before and in combination with cholesterol-lowering medication, is a critical component of health promotion and ASCVD risk reduction.

What is added by this report?

During 2005-2012, among the estimated 78 million U.S. adults aged $\geq 21$ years eligible for treatment, $55.5 \%$ were taking cholesterol-lowering medication and $46.6 \%$ reported making lifestyle modifications at baseline. Differences in medication use exist among sex and racial/ethnic groups.

What are the implications for public health practice?

Further efforts by clinicians and public health practitioners are needed to implement complementary and targeted patient education and disease management programs to reduce sex and racial/ethnic disparities among adults eligible for treatment of cholesterol.

${ }^{1}$ Divison of Heart Disease and Stroke Prevention, National Center for Chronic Disease Prevention and Health Promotion, CDC; ${ }^{2}$ Emory University School of Medicine, Atlanta, Georgia; ${ }^{3}$ Rollins School of Public Health, Emory University, Atlanta, Georgia.

Corresponding author: Carla Mercado, cmercado@cdc.gov, 770-488-8075.

\section{References}

1. Mozaffarian D, Benjamin EJ, Go AS, et al. Heart disease and stroke statistics - 2015 update: a report from the American Heart Association. Circulation 2015;131:e29-322.

2. Kuklina EV, Carroll MD, Shaw KM, Hirsch R. Trends in high LDL cholesterol, cholesterol-lowering medication use, and dietary saturated-fat intake: United States, 1976-2010. NCHS data brief, no 117. Hyattsville, MD: National Center for Health Statistics, US Department of Health and Human Services, CDC; 2013. Available at http://www.cdc.gov/nchs/ data/databriefs/db117.pdf.
3. Carroll MD, Fryar CD, Kit BK. Total and high-density lipoprotein cholesterol in adults: United States, 2011-2014. NCHS data brief, no 226. Hyattsville, MD: National Center for Health Statistics, US Department of Health and Human Services, CDC; 2015. Available at http://www.cdc.gov/nchs/data/databriefs/db226.pdf.

4. Gu Q, Paulose-Ram R, Burt VL, Kit BK. Prescription cholesterollowering medication use in adults aged 40 and over: United States, 2003-2012. NCHS data brief, no 177. Hyattsville, MD: National Center for Health Statistics, US Department of Health and Human Services, CDC; 2014. Available at http://www.cdc.gov/nchs/data/ databriefs/db177.pdf.

5. Stone NJ, Robinson JG, Lichtenstein AH, et al. 2013 ACC/AHA guideline on the treatment of blood cholesterol to reduce atherosclerotic cardiovascular risk in adults: a report of the American College of Cardiology/American Heart Association Task Force on Practice Guidelines. J Am Coll Cardiol 2014;63:2889-934.

6. Goff DC Jr, Lloyd-Jones DM, Bennett G, et al. 2013 ACC/AHA guideline on the assessment of cardiovascular risk: a report of the American College of Cardiology/American Heart Association task force on practice guidelines. J Am Coll Cardiol 2014;63:2935-59.

7. Pencina MJ, Navar-Boggan AM, D’Agostino RB Sr, et al. Application of new cholesterol guidelines to a population-based sample. $\mathrm{N}$ Engl J Med 2014;370:1422-31.

8. Eckel RH, Jakicic JM, Ard JD, et al. 2013 AHA/ACC guideline on lifestyle management to reduce cardiovascular risk: a report of the American College of Cardiology/American Heart Association Task Force on Practice Guidelines. J Am Coll Cardiol 2014;63:2960-84.

9. Friedewald WT, Levy RI, Fredrickson DS. Estimation of the concentration of low-density lipoprotein cholesterol in plasma, without use of the preparative ultracentrifuge. Clin Chem 1972;18:499-502.

10. Sarpong EM, Zuvekas SH. Trends in statin therapy among adults (age $\geq 18$ ), United States, 2000 to 2011. Statistical brief \#458. Rockville, MD: Agency for Healthcare Research and Quality; 2014. Available at http://meps.ahrq.gov/mepsweb/data_files/publications/st458/stat458.pdf.

11. US Department of Health and Human Services. Healthy people 2020: heart disease and stroke. Washington DC: US Department of Health and Human Services; 2013. Available at http://www.healthypeople. gov/2020/topics-objectives/topic/heart-disease-and-stroke.

12. Frieden TR, Berwick DM. The "Million Hearts" initiative—-preventing heart attacks and strokes. N Engl J Med 2011;365:e27. 


\title{
CDC Grand Rounds: Prevention and Control of Skin Cancer
}

\author{
Meg Watson, $\mathrm{MPH}^{1}$; Cheryll C. Thomas, $\mathrm{MSPH}^{1}$; Greta M. Massetti, $\mathrm{PhD}^{1}$; Sharon McKenna ${ }^{2}$; Jeffrey E. Gershenwald, MD³;
} Susan Laird, MSN ${ }^{4}$; John Iskander, $\mathrm{MD}^{4}$; Boris Lushniak, $\mathrm{MD}^{5}$

Skin cancer is the most common cancer in the United States, and most cases are preventable (1). Persons with certain genetic risk factors, including having a lighter natural skin color; blue or green eyes; red or blonde hair; dysplastic nevi or a large number of common moles; and skin that burns, freckles, or reddens easily or becomes painful after time in the sun, have increased risk for skin cancer (1). Persons with a family or personal history of skin cancer, especially melanoma, are also at increased risk. Although these genetic factors contribute to individual risk, most skin cancers are also strongly associated with ultraviolet (UV) radiation exposure. Most UV exposure comes from the sun, although some persons use UV-emitting indoor tanning devices (e.g., beds, booths, and lamps).

The three most common types of skin cancer, in descending order, are basal cell carcinoma, squamous cell carcinoma, and melanoma (1). Basal cell carcinoma alone is thought to be more common than any other cancer, but central cancer registries* (CCRs) do not collect data on basal cell carcinoma, so incidence is unknown. Squamous cell carcinoma is less common than basal cell carcinoma and can cause death, although most cases are treatable. Melanoma is the least common of the three main types of skin cancer, but causes the most deaths. In 2012, CCRs in the United States reported approximately 67,000 new melanoma cases and 9,000 deaths from melanoma (2).

Overall, rates of melanoma incidence are approximately $60 \%$ higher among men than women (25.5 and 15.9 per 100,000, respectively, in 2012), and rates increase rapidly after age 50 years. However, among persons aged $<50$ years, melanoma is more common among women (2).

Rates of skin cancer have tripled since the early 1970s. Although much of the increase has been among early stage cancers, and mortality has remained relatively stable, more recent analyses have found increases among later stage cancers, and mortality rates for males have begun to increase (3).

Differences by race in skin cancer risk are largely related to differences in skin type and other genetic risk factors. The rate

\footnotetext{
${ }^{*}$ Central cancer registries collect detailed information on cancer patients from a defined geographic area or a specific population.
}

This is another in a series of occasional MMWR reports titled $C D C$ Grand Rounds. These reports are based on grand rounds presentations at CDC on high-profile issues in public health science, practice, and policy. Information about CDC Grand Rounds is available at http://www.cdc.gov/about/grand-rounds. of melanoma in non-Hispanic whites (whites) is approximately 25 times higher than the rate in blacks and six times higher than the rate in Hispanics. However, a diagnosis of melanoma in blacks and Hispanics often occurs later than in whites, which has led to poorer survival rates (1).

The causal relationship between UV exposure and skin cancer among populations with comparatively more sun-sensitive skin is well established, and recent genetic research has found a UV exposure signature among mutations specific to melanoma (4). However, $37 \%$ of persons in the United States report getting sunburned each year, with the highest rate (65\%) among white adults aged $<30$ years (5). Among persons reporting sunburn, $12 \%$ report four or more burns during the past year (5). Approximately $67 \%$ of men and $73 \%$ of women report using at least one method of sun protection when outdoors for $>1$ hour on a sunny day (G). However, use of each individual method of protection (e.g., sunscreen, hats, shade, and protective clothing) is substantially lower, especially among men. For example, only $21 \%$ of men and $41 \%$ of women report wearing sunscreen when outdoors for $>1$ hour on a sunny day. Although women tend to report higher rates of sun protection, intentional UV exposures, including sunbathing and indoor tanning, are more common among younger women than men (1). Only $10 \%$ of high school students report wearing sunscreen when outdoors for $>1$ hour on a sunny day ( 7 ). An estimated 11.6 million persons in the United States, including almost one in three white women aged 16-25 years, tan indoors each year (8-10). The U.S. Food and Drug Administration (FDA) recently reclassified tanning devices to better reflect their risk level, and requires that devices include warnings stating that their use is contraindicated for persons aged $<18$ years (11).

\section{Evidence-Based Skin Cancer Prevention}

Many skin cancers can be prevented by the strategies promulgated in the Surgeon General's Call to Action to Prevent Skin Cancer (Call to Action) (1):

Increase opportunities for sun protection in outdoor settings. Increasing shade and other opportunities for sun protection in outdoor recreational settings like parks, sports arenas, pools, beaches, and ski resorts can help reduce UV overexposure and support individual sun protection behaviors. Likewise, efforts to increase shade and provide support for other methods of sun protection in schools and occupational settings are important, especially for recess and other outdoor school activity areas and for outdoor work environments. 
Provide individuals with the information they need to make informed, healthy choices about UV exposure. The general public often does not understand the widely available information on the UV Index. ${ }^{\dagger}$ Effective messages with prompts on using sun protection when the UV Index is high might help increase use of sun protection at schools and in occupational settings. The U.S. Preventive Services Task Force recommends counseling children, adolescents, and young adults aged 10-24 years who have fair skin about minimizing their exposure to UV to reduce risk for skin cancer. ${ }^{\S}$ Aligning sun protection messages with other physical activity and outdoor recreation messages, such as reminders to wear widebrimmed hats when walking or to reapply sunscreen during water breaks, might provide an opportunity to address multiple important public health goals.

Promote policies that advance the national goal of preventing skin cancer. Policies at all levels, including federal, state, local, and institutional policies in workplaces, schools, and businesses, can help support skin cancer prevention. School policies that prohibit hats or student possession of sunscreen can create barriers to the use of these important sun protection methods. School and workplace policies that support sun protection include education on UV exposure, providing shade at school or work, and encouraging students and employees to use sun protection. Organizational or municipal shade policies can require the provision of shade when constructing or refurbishing public facilities or schools, thereby increasing the availability of shade $(1,12)$.

Reduce harms from indoor tanning. UV from indoor tanning devices has been classified by the World Health Organization and the U.S. Department of Health and Human Services as a known human carcinogen. Federal, state, and local regulations have recently increased; 13 states, the District of Columbia, and several cities and counties have now banned the use of indoor tanning beds for persons aged $<18$ years (13); however, tanning is particularly common among young adult white women and in areas near college campuses. The availability of tanning devices in less-regulated settings, such as homes, gyms, and apartment building common areas, can pose unique challenges for enforcing regulations.

Strengthen research, surveillance, monitoring, and evaluation related to skin cancer prevention. A better understanding of the role of UV exposure in skin cancer and evaluation of interventions

\footnotetext{
${ }^{\dagger}$ The UV Index, developed by the National Weather Service and the U.S. Environmental Protection Agency, provides a daily forecast of the expected risk for overexposure to the sun. The index predicts UV radiation intensity levels on a scale of 1 to $11+$, with 1 indicating a low risk for overexposure and 11+ signifying an extreme risk. Calculated on a next-day basis for every zip code across the United States, the UV Index takes into account clouds and other local conditions that affect the amount of UV radiation reaching the ground in different parts of the country.

$\$$ More information available at http://www.uspreventiveservicestaskforce.org/ Page/Document/UpdateSummaryFinal/skin-cancer-counseling.
}

to reduce overexposure to UV can help inform future prevention efforts. Although providers are required to report melanomas to CCRs, many in situ and early stage invasive melanomas are diagnosed and treated in outpatient settings, which often lack the reporting infrastructure found in hospital settings (1). Developing methods to better measure the prevalence of basal cell carcinoma and squamous cell carcinoma could also provide important information to measure the impact of public health efforts.

\section{Implementation and Impact of Prevention Strategies}

The Call to Action names various sectors as partners in prevention: policymakers; businesses and employers; health care systems, insurers, and clinicians; early learning centers, schools, colleges, and universities; community, nonprofit, and faith-based organizations; and persons and families (1). Some partners, such as the Arizona Department of Health Services and The University of Texas MD Anderson Cancer Center (MD Anderson), have implemented some of the prevention strategies named in the Call to Action through their previous and current work; other partners implemented these strategies after the release of the Call to Action.

The state of Arizona names sun safety as a top public health priority, and its previous and current work has addressed several of the Call to Action strategies. The SunWise program, developed by the U.S. Environmental Protection Agency and now supported by the National Environmental Education Foundation, is a health and environmental education program that teaches children how to protect themselves from overexposure to the sun (14). Beginning in 2005, Arizona state law has required that the SunWise program be incorporated as part of school education curricula for public school students in kindergarten through 8 th grade $(\mathrm{K}-8)$. Recently, Arizona expanded the requirement to include state-licensed early learning center providers, and the requirement could be voluntarily adopted by private schools or by organizations such as sports teams and summer camps. Educators in Arizona's K-8 schools have access to school policy template language to make it easier to implement sun safety practices. Arizona officials are also working to improve melanoma reporting to the state's CCR.

A multidisciplinary team at MD Anderson is focusing on melanoma treatment and prevention through a program called the "Melanoma Moon Shot" that seeks to accelerate the pace that scientific discoveries are converted into clinical practices (http:// www.cancermoonshots.org/cancer-types/melanoma). Studies of melanoma cancer genes are providing more information on the etiology and clinical behavior of melanoma, with the goal of increasing long-term survival rates and improving the antitumor immune response. Researchers are also investigating interventions to increase sun protective behaviors in children (e.g., Ray and the Sunbeatables: A Sun Safety Curriculum for Preschoolers) (15), and to use appearance-focused interventions (e.g., highlighting 
UV-related skin damage) to impact tanning behaviors and attitudes in middle school students. MD Anderson served as an important resource for educating the Texas legislature on the risks of indoor tanning and sunscreen use in schools. In 2013, Texas passed legislation that prohibits the use of indoor tanning facilities by persons aged $<18$ years (16), and in June 2015 , the state passed legislation that permits public school students to "possess and use a topical sunscreen product while on school property or at a school-related event or activity to avoid overexposure to the sun ... if the product is approved by the federal Food and Drug Administration for over-the-counter sunscreen products use" (17).

Cities have also been active in developing easy-to-implement sun-safe practices. The city of Miami Beach, Florida, has collaborated with Miami Beach's Mount Sinai Hospital to provide 50 free sunscreen dispensers on beaches and in parks. The city of Boston, Massachusetts, has provided 30 free sunscreen dispensers in citywide parks in collaboration with nonprofit organizations. A goal of the city of Montclair, New Jersey, is to become the "sun-smartest city in America" by working to implement all of the strategies outlined in the Call to Action. Other parks and recreation resources are available at http://www.cdc.gov/cancer/ skin/pdf/skincancer_parks-recreation.pdf.

\section{Future Impact of Prevention Efforts}

In the United States, an estimated total of $\$ 8.1$ billion is spent annually on treatment for all skin cancers combined, and costs have been increasing in recent years (18). Without communitywide intervention programs, the annual cost of treating newly diagnosed melanoma cases is estimated to increase approximately $250 \%$ from $2011-2030$ (from $\$ 457$ million to $\$ 1.6$ billion) (19). However, comprehensive skin cancer prevention programs to reduce sun exposure, facilitate sun protection, prevent sunburn, and reduce indoor tanning can reduce future cases of skin cancer, and can be cost-effective. Prevention programs in Australia have been estimated to save AU $\$ 2.30$ for every AU $\$ 1$ invested (20). Implementation of communitywide programs in the United States has the potential to annually avert an estimated 230,000 melanoma cases and prevent $\$ 2.7$ billion in costs for newly diagnosed melanomas (19).

\footnotetext{
${ }^{1}$ Division of Cancer Prevention, National Center for Chronic Disease Prevention and Health Promotion, CDC; ${ }^{2}$ Arizona SunWise Skin Cancer Prevention Program, Arizona Department of Health Services; ${ }^{3}$ The University of Texas MD Anderson Cancer Center, Houston, Texas; ${ }^{4}$ Office of the Associate Director for Science, CDC; ${ }^{5}$ Office of the Surgeon General, U.S. Department of Health and Human Services.

Corresponding author: Meg Watson, MWatson2@cdc.gov, 770-488-3097.

\section{References}

1. US Department of Health and Human Services. The Surgeon General's call to action to prevent skin cancer. Washington DC: US Department of Health and Human Services, Office of the Surgeon General; 2014. Available at http://www.surgeongeneral.gov/library/calls/prevent-skin-cancer.
}

2. US Cancer Statistics Working Group. United States cancer statistics: 1999-2012 incidence and mortality web-based report. Atlanta, GA: US Department of Health and Human Services, CDC and National Institutes of Health, National Cancer Institute; 2015. Available at https:// nccd.cdc.gov/uscs.

3. Jemal A, Saraiya M, Patel P, et al. Recent trends in cutaneous melanoma incidence and death rates in the United States, 1992-2006. J Am Acad Dermatol 2011;65(5 Suppl 1):S17.e01-e1.

4. Cancer Genome Atlas Network. Genomic classification of cutaneous melanoma. Cell 2015;161:1681-96.

5. Holman DM, Berkowitz Z, Guy GP Jr, Hartman AM, Perna FM. The association between demographic and behavioral characteristics and sunburn among U.S. adults-National Health Interview Survey, 2010. Prev Med 2014;63:6-12.

6. CDC. National Health Interview Survey. Atlanta, GA: US Department of Health and Human Services, CDC; 2013. Available at http://www. cdc.gov/nchs/nhis.htm.

7. Kann L, Kinchen S, Shanklin SL, et al. Youth risk behavior surveillanceUnited States, 2013. MMWR Surveill Summ 2014;63(No. SS-4).

8. Guy GP Jr, Berkowitz Z, Holman DM, Hartman AM. Recent changes in the prevalence of and factors associated with frequency of indoor tanning among US adults. JAMA Dermatol 2015;151:1256-9.

9. Guy GP Jr, Berkowitz Z, Everett Jones S, Holman DM, Garnett E, Watson M. Trends in indoor tanning among US high school students, 2009-2013. JAMA Dermatol 2015;151:448-50.

10. Guy GP Jr, Berkowitz Z, Watson M, Holman DM, Richardson LC. Indoor tanning among young non-Hispanic white females. JAMA Intern Med 2013;173:1920-2.

11. US Food and Drug Administration. FDA to require warnings on sunlamp products [News Release]. Washington, DC: US Food and Drug Administration; 2014. Available at http://www.fda.gov/NewsEvents/ Newsroom/PressAnnouncements/ucm399222.htm.

12. CDC. Shade planning for America's schools. Atlanta, GA: US Department of Health and Human Services, CDC; 2008. Available at http://www.cdc.gov/cancer/skin/pdf/shade_planning.pdf.

13. National Conference of State Legislatures. Indoor tanning restrictions for minors-a state-by-state comparison. Denver, CO: National Conference of State Legislatures; 2015. Available at http://www.ncsl. org/issues-research/health/indoor-tanning-restrictions.aspx.

14. US Environmental Protection Agency. SunWise. Washington, DC: US Environmental Protection Agency; 2015. Available at http://www2.epa. gov/sunwise.

15. MD Anderson Cancer Center. Helping preschoolers deploy 'superpowers' against sunburn: Ray and the Sunbeatables debut through CATCH; arise from MD Anderson research. Houston, TX: The University of Texas, MD Anderson Cancer Center; 2015. Available at http://www. mdanderson.org/newsroom/news-releases/2015/helping-preschoolersdeploy-superpowers-against-sunburn.html.

16. State of Texas. Relating to a prohibition on the use of a tanning facility by a minor. State Bill No. 329 (September 1, 2013). Available at http:// www.legis.state.tx.us/BillLookup/History.aspx?LegSess=83R\&Bill=SB329.

17. State of Texas. Relating to student use of sunscreen products in public schools. State Bill No. 265 (June 19, 2015). Available at http://www. legis.state.tx.us/BillLookup/History.aspx?LegSess=84R\&Bill=SB265.

18. Guy GP Jr, Machlin SR, Ekwueme DU, Yabroff KR. Prevalence and costs of skin cancer treatment in the U.S., 2002-2006 and 2007-2011. Am J Prev Med 2015;48:183-7.

19. Guy GP Jr, Thomas CC, Thompson T, Watson M, Massetti GM, Richardson LC. Vital signs: melanoma incidence and mortality trends and projections-United States, 1982-2030. MMWR Morb Mortal Wkly Rep 2015;64:591-6.

20. Shih ST, Carter R, Sinclair C, Mihalopoulos C, Vos T. Economic evaluation of skin cancer prevention in Australia. Prev Med 2009;49:449-53. 


\section{Carbapenem-resistant Enterobacteriaceae Producing OXA-48-like Carbapenemases - United States, 2010-2015}

Meghan Lyman, MD ${ }^{1,2}$; Maroya Walters, $\mathrm{PhD}^{2}$;

David Lonsway, $\mathrm{MMSc}^{2}$; Kamile Rasheed, $\mathrm{PhD}^{2}$;

Brandi Limbago, $\mathrm{PhD}^{2}$; Alexander Kallen, $\mathrm{MD}^{2}$

Carbapenem-resistant Enterobacteriaceae (CRE) are bacteria that are often resistant to most classes of antibiotics and cause health care-associated infections with high mortality rates (1). Among CRE, strains that carry plasmid-encoded carbapenemase enzymes that inactivate carbapenem antibiotics are of greatest public health concern because of their potential for rapid global dissemination, as evidenced by the increasing distribution of CRE that produce the Klebsiella pneumoniae carbapenemase and the New Delhi metallo- $\beta$-lactamase. Newly described resistance in Enterobacteriaceae, such as plasmid-mediated resistance to the last-line antimicrobial colistin, recently detected in China, and resistance to the newly approved antimicrobial, ceftazidime-avibactam, identified from a U.S. K. pneumoniae carbapenemase-producing isolate, highlight the continued urgency to delay spread of CRE $(2,3)$. Monitoring the emergence of carbapenemases is crucial to limiting their spread; identification of patients carrying carbapenemase-producing CRE should result in the institution of transmission-based precautions and enhanced environmental cleaning to prevent transmission.* The OXA48 carbapenemase was first identified in Enterobacteriaceae in Turkey in 2001 (2), and OXA-48-like variants have subsequently been reported around the world. The first U.S. reports of OXA-48-like carbapenemases were published in 2013 and included retrospectively identified isolates from 2009 (3) and two isolates collected in 2012 from patients in Virginia who had recently been hospitalized outside the United States (4). Although there are limited additional published reports from the United States (5), CDC continues to receive reprots of these organisms. This report describes patients identified as carrying CRE producing OXA-48-like carbapenemases in the United States during June 2010-August 2015.

CDC received reports of $52 \mathrm{CRE}$ isolates producing OXA-48like carbapenemases collected from 43 patients in 19 states during June 2010-August 2015 (Figure); seven of these isolates were identified retrospectively from six patients. Eight isolates from four patients were part of two different clusters in the United

\footnotetext{
*2012 CRE Toolkit - Guidance for Control of Carbapenem-resistant Enterobacteriaceae. Available at http://www.cdc.gov/hai/organisms/cre/cretoolkit/index.html.
}

FIGURE. Number of reported patients with carbapenem-resistant Enterobacteriaceae producing OXA-48-like carbapenemases ( $N=43$ ) - United States, June 2010-August 2015

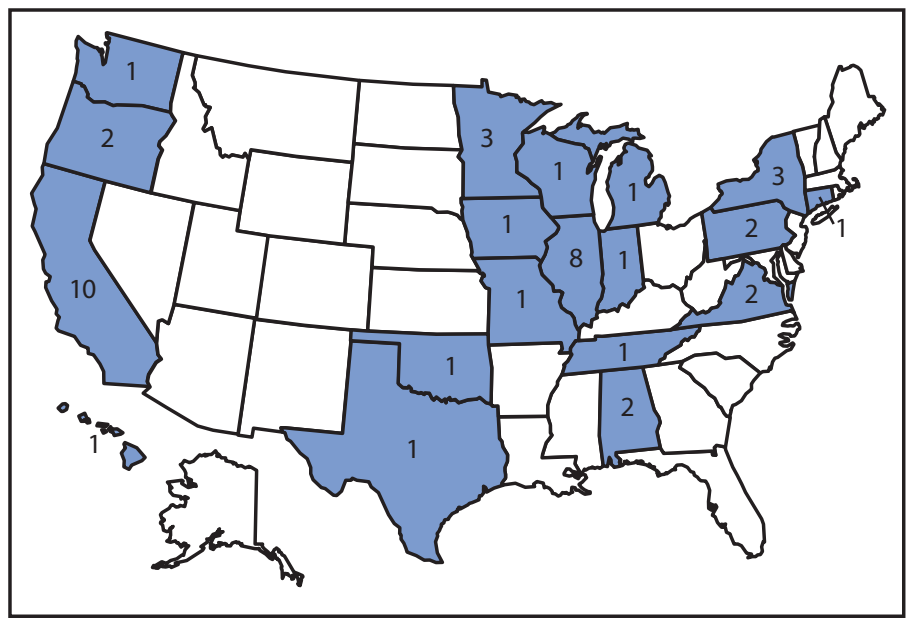

States during 2014. The number of patients from whom CRE isolates producing OXA-48-like carbapenemases were identified ranged from one in 2010 to 11 per year in 2013, 2014, and 2015. Thirty-five patients (81\%) had OXA-48-like carbapenemase identified from $K$. pneumoniae isolates, seven (16\%) from Escherichia coli isolates, one (2\%) from an Enterobacter aerogenes isolate, and one (2\%) from a Klebsiella ozaenae isolate; two of which were isolates of different species from a single patient. Isolates with both New Delhi metallo- $\beta$-lactamase and OXA48-like carbapenemase genes were obtained from five patients (12\%). The most common sources were urine (22 patients [51\%]) and respiratory specimens (nine patients [21\%]).

The median age among 35 (81\%) patients for whom age was reported was 70 years (range $=29-91$ years). Among 29 patients for whom a travel history was available, 19 (66\%) had traveled internationally during the year before specimen collection, and 16 (55\%) were hospitalized outside the United States for $\geq 1$ night; these percentages increased to $76 \%$ and $64 \%$, respectively, when cases associated with the two domestic clusters were excluded. India was the most frequently reported destination among patients with international travel (11 of 19 patients) and international hospitalization (nine of 16).

CRE producing OXA-48-like carbapenemases have demonstrated the ability to spread in other countries $(\sigma)$ and cause outbreaks in health care settings. Factors potentially contributing to the spread of these organisms include the high transfer efficiency of the plasmid containing OXA-48-like genes $(\sigma)$ and challenges in identifying these organisms. These challenges in identification occur because of the limited testing for CRE 
Morbidity and Mortality Weekly Report

resistance mechanisms in U.S. clinical laboratories and the different susceptibility profiles of these organisms compared with other carbapenemase-producing CRE, making them difficult to differentiate from CRE that do not produce carbapenemases (organisms producing OXA-48-like carbapenemases might be susceptible to third generation cephalosporins). The modification of the CDC CRE surveillance definition in January 2015 to include organisms that are resistant to ertapenem or that possess a carbapenemase gene should improve sensitivity for detecting OXA-48-producing CRE (7).

Although clusters of CRE expressing OXA-48-like carbapenemases suggest transmission has occurred in the United States, the majority of identified patients were reported to have had exposure to health care outside the United States. This is consistent with recommendations in the CDC Health Advisory from February 2013 (8), which sought to prevent transmission of isolates producing non-K. pneumoniae carbapenemases by improving their detection in patients recently hospitalized outside the United States. Recommendations include determining the mechanism of resistance for any CRE isolated from such patients and considering CRE screening of these patients on admission.

\footnotetext{
${ }^{1}$ Epidemic Intelligence Service, CDC; ${ }^{2}$ Division of Healthcare Quality Promotion, National Center for Emerging and Zoonotic Infectious Diseases, CDC.

Corresponding author: Meghan M. Lyman, mmlyman@cdc.gov, 404-639-4241.
}

\section{References}

1. Gupta N, Limbago BM, Patel JB, Kallen AJ. Carbapenem-resistant Enterobacteriaceae: epidemiology and prevention. Clin Infect Dis 2011;53:60-7.

2. Liu Y, Wang Y, Walsh TR, et al. Emergence of plasmid-mediated colistin resistance mechanism MCR-1 in animals and human beings in China: a microbiological and molecular biological study. Lancet. Epub Nov 18, 2015.

3. Humphries RM, Yang S, Hemarajata P, et al. First report of ceftazidimeavibactam resistance in a KPC-3-expressing Klebsiella pneumoniae isolate. Antimicrob Agents Chemother 2015;59:6605-7.

4. Poirel L, Potron A, Nordmann P. OXA-48-like carbapenemases: the phantom menace. J Antimicrob Chemother 2012;67:1597-606.

5. Lascols C, Peirano G, Hackel M, Laupland KB, Pitout JD. Surveillance and molecular epidemiology of Klebsiella pneumoniae isolates that produce carbapenemases: first report of OXA-48-like enzymes in North America. Antimicrob Agents Chemother 2013;57:130-6.

6. Mathers AJ, Hazen KC, Carroll J, et al. First clinical cases of OXA-48producing carbapenem-resistant Klebsiella pneumoniae in the United States: the "menace" arrives in the new world. J Clin Microbiol 2013;51:680-3.

7. Doi Y, O'Hara JA, Lando JF, et al. Co-production of NDM-1 and OXA232 by Klebsiella pneumoniae. Emerg Infect Dis 2014;20:163-5.

8. Nordmann P, Poirel L. The difficult-to-control spread of carbapenemase producers among Enterobacteriaceae worldwide. Clin Microbiol Infect 2014;20:821-30.

9. CDC. FAQs about choosing and implementing a CRE definition. CDC Healthcare-associated infections. Atlanta, GA: US Department of Health and Human Services, CDC. Available at http://www.cdc.gov/hai/ organisms/cre/definition.html.

10. CDC Health Alert Network. New carbapenem-resistant enterobacteriaceae warrant additional action by healthcare providers. Atlanta, GA: US Department of Health and Human Services, CDC; 2013. Available at http://emergency.cdc.gov/han/han00341.asp. 
Morbidity and Mortality Weekly Report

\section{Increase in Human Cases of Tularemia - Colorado, Nebraska, South Dakota, and Wyoming, January-September 2015}

Caitlin Pedati, $\mathrm{MD}^{1,2}$; Jennifer House, DVM³ ; Jessica Hancock-Allen, $\mathrm{MPH}^{1,3}$; Leah Colton, $\mathrm{PhD}^{3}$; Katie Bryan, $\mathrm{MPH}^{4}$; Dustin Ortbahn ${ }^{5}$; Lon Kightlinger, $\mathrm{PhD}^{5}$; Kiersten Kugeler, $\mathrm{PhD}^{6}$; Jeannine Petersen, $\mathrm{PhD}^{6}$; Paul Mead, MD ${ }^{6}$; Tom Safranek MD ${ }^{2}$; Bryan Buss DVM ${ }^{2,7}$

Tularemia is a rare, often serious disease caused by a gram-negative coccobacillus, Francisella tularensis, which infects humans and animals in the Northern Hemisphere (1). Approximately 125 cases have been reported annually in the United States during the last two decades (2). As of September 30, a total of 100 tularemia cases were reported in 2015 among residents of Colorado $(n=43)$, Nebraska $(n=21)$, South Dakota $(\mathrm{n}=20)$, and Wyoming $(\mathrm{n}=16)$ (Figure). This represents a substantial increase in the annual mean number of four (975\% increase), seven (200\%), seven (186\%) and two $(70 \%)$ cases, respectively, reported in each state during 2004-2014 (2).

Patients ranged in age from 10 months to 89 years (median $=56$ years); 74 were male. The most common clinical presentations of tularemia were respiratory disease (pneumonic form, $[\mathrm{n}=26]$ ), skin lesions with lymphadenopathy (ulceroglandular form, $[\mathrm{n}=26]$ ), and a general febrile illness without localizing signs (typhoidal form, $[\mathrm{n}=25]$ ). Overall, 48 persons were hospitalized, and one death was reported, in a man aged 85 years. Possible reported exposure routes included animal contact $(n=51)$, environmental aerosolizing activities $(n=49)$, and arthropod bites $(n=34)$; a total of 41 patients reported two or more possible exposures.

Clinical presentation and severity of tularemia depends on the strain, inoculation route, and infectious dose. Tularemia can be transmitted to humans by direct contact with infected animals (e.g., rabbits or cats); ingestion of contaminated food, water, or soil; inhalation from aerosolization (e.g., landscaping, mowing over voles, hares, and rodents, or other farming activities); or arthropod bites (e.g., ticks or deer flies) $(1,3)$. Humanto-human transmission has never been demonstrated $(1,3)$.

Infected persons can develop a range of symptoms that display several clinical forms. These include fever and chills with muscle and joint pain (typhoidal), cough or difficulty breathing (pneumonic), swollen lymph nodes with or without skin lesions (ulceroglandular or glandular), conjunctivitis (oculoglandular), pharyngitis (oropharyngeal), or abdominal pain with vomiting and diarrhea (intestinal) $(2,3)$. Symptoms typically begin within 3-5 days of exposure, but can take up to 14 days to appear. Case fatality rates range from $<2 \%-24 \%$, depending on the strain (1-3). Streptomycin is considered the drug of choice on the basis of historical use and Food and Drug Administration approval; however, it sometimes can be difficult to obtain and is associated with frequent ototoxicity (3). Gentamicin, doxycycline, and ciprofloxacin are also used $(2,3)$.

F. tularensis is commonly isolated in culture or detected by polymerase chain reaction from patients' blood specimens, but can also be identified in specimens from skin lesions, spinal fluid, lymph nodes, and respiratory secretions (2). In addition, a serologic diagnosis can be made by demonstrating a fourfold increase between immunoglobulin $\mathrm{G}$ titers from patients in the acute and convalescent stages of infection. Specimens suspected of containing $F$. tularensis should be handled at biosafety level 2 at a minimum. Biosafety level 3 containment is recommended when handling live cultures $(2,3)$.

Although the cause for the increases in tularemia cases in Colorado, Nebraska, South Dakota, and Wyoming is unclear, possible explanations might be contributing factors, including increased rainfall promoting vegetation growth, pathogen survival, and increased rodent and rabbit populations. Increased awareness and testing since tularemia was reinstated as a nationally notifiable disease in January 2000 is also a possible

FIGURE. Geographic distribution of reported tularemia cases Colorado, Nebraska, South Dakota, and Wyoming,* JanuarySeptember, 2015

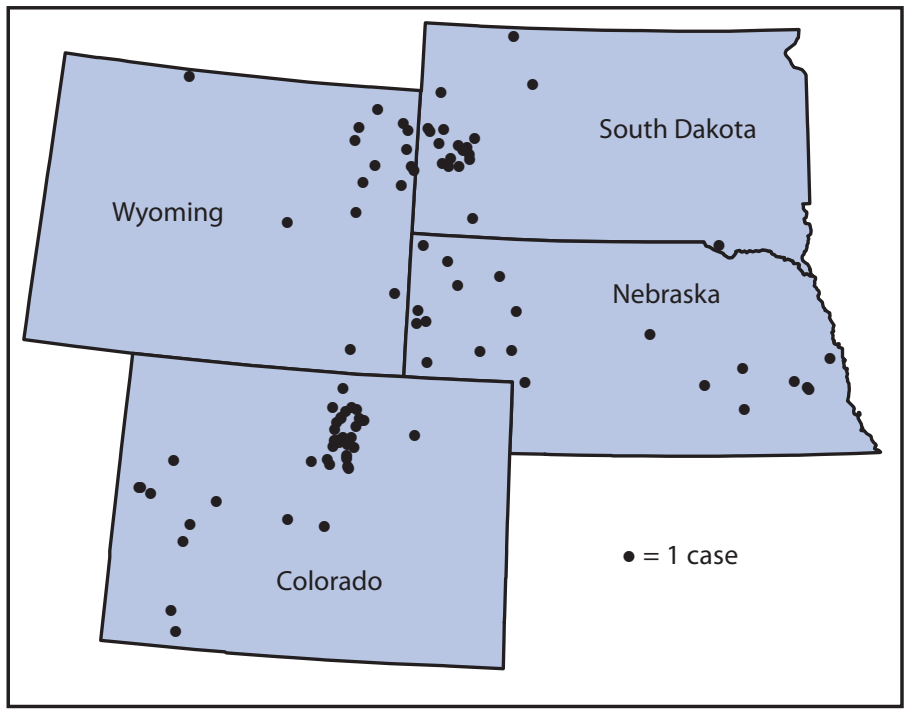

Source: Map of local health departments in Nebraska from Nebraska Department of Health and Human Services (available at http://dhhs.ne.gov/ publichealth/Documents/LHDMap.pdf).

* Dots indicating cases in Colorado, South Dakota, and Wyoming are assigned randomly within zip codes; dots indicating cases in Nebraska are assigned randomly within local health department jurisdiction. 
explanation for the increase in the number of cases in these four states (4). Health care providers should be aware of the elevated risk for tularemia within these states* and consider a diagnosis of tularemia in any person nationwide with compatible signs and symptoms. Residents and visitors to these areas should regularly use insect repellent, wear gloves when handling animals, and avoid mowing in areas where sick or dead animals have been reported. Additional information is available at http://www.cdc.gov/tularemia.

\footnotetext{
* As part of this investigation, all bordering states were contacted, and no others reported a similar twofold to threefold increase above baseline for tularemia cases in 2015.
}

${ }^{1}$ Epidemic Intelligence Service, Division of Scientific Education and Professional Development, CDC; ${ }^{2}$ Nebraska Department of Health and Human Services; ${ }^{3}$ Colorado Department of Public Health and Environment; ${ }^{4}$ Wyoming Department of Health; ${ }^{5}$ South Dakota Department of Health; ${ }^{6}$ Division of Vector-Borne Diseases, National Center for Emerging and Zoonotic Infectious Diseases, CDC; ${ }^{7}$ Division of State and Local Readiness, Office of Public Health Preparedness and Response, CDC.

Corresponding author: Caitlin Pedati, CPedati@cdc.gov, 402-471-9148.

\section{References}

1. Penn RL. Francisella tularensis (tularemia) [Chapter 229]. In: Bennett JE, Dolin R, Blaser MJ, eds. Mandell, Douglas, and Bennett's Principles and Practice of Infectious Disease. 8th ed. Philadelphia, PA: Elsevier Saunders; 2015.

2. CDC. Tularemia-United States, 2001-2010. MMWR Morb Mortal Wkly Rep 2013;62:963-6.

3. World Health Organization. WHO guidelines on tularemia. Geneva, Switzerland: World Health Organization; 2007. Available at http://www. cdc.gov/tularemia/resources/whotularemiamanual.pdf.

4. CDC. Summary of notifiable diseases, United States, 1998. MMWR Morb Mortal Wkly Rep 1999;47 (No. 53). 


\section{Recommendation Regarding Education Programs and Policies to Promote Health Equity from the Community Preventive Services Task Force}

The Community Preventive Services Task Force recently posted new information on its website entitled, "Promoting Health Equity Through Education Programs and Policies: School-Based Health Centers." The information is available at http://www.thecommunityguide.org/healthequity/education/ schoolbasedhealthcenters.html.

Established in 1996 by the U.S. Department of Health and Human Services, the task force is an independent, nonfederal, uncompensated panel of public health and prevention experts whose members are appointed by the Director of CDC. The task force provides information for a wide range of decision makers on programs, services, and policies aimed at improving population health. Although CDC provides administrative, research, and technical support for the task force, the recommendations developed are those of the task force and do not undergo review or approval by CDC.

\section{National Influenza Vaccination Week - December 6-12, 2015}

The U.S. Department of Health and Human Services, CDC, state and local health departments, and other partners will observe National Influenza Vaccination Week (NIVW) during December 6-12, 2015, with educational and promotional activities across the country.

Beginning in 2005, NIVW was established to highlight the importance of annual influenza vaccination and to foster greater use of influenza vaccine during the months of December, January, and beyond. As of November 13, 2015, approximately 133 million doses of 2015-2016 seasonal influenza vaccine have been distributed to vaccination providers in the United States (1).

The Advisory Committee on Immunization Practices recommends influenza vaccination for all persons aged $\geq 6$ months (2), with rare exceptions. Influenza vaccination is especially important for persons in certain groups who are at higher risk for influenza-related complications. Those high-risk groups include children aged $<5$ years, but especially children aged $<2$ years; persons with certain chronic health conditions, such as heart disease, asthma, and diabetes; pregnant women; and adults aged $\geq 65$ years. Health care personnel are at risk for acquiring influenza and transmitting it to their patients (3).

Information about event-specific educational materials, web tools, and CDC's planned activities for NIVW is available at http://www.cdc.gov/flu/nivw/index.htm, and general materials are available at http://www.cdc.gov/flu/freeresources. Additional information and resources for health care professionals and patients are available at http://www.cdc.gov/flu/professionals/.

Influenza vaccination coverage estimates for 2014-2015 are available at http://www.cdc.gov/flu/fluvaxview. Interim vaccination coverage estimates for 2015-2016 will be released during NIVW.

\section{References}

1. CDC. Seasonal influenza vaccine and total doses distributed. Atlanta, GA: US Department of Health and Human Services, CDC; 2015. Available at http://www.cdc.gov/flu/professionals/vaccination/ vaccinesupply.htm.

2. Grohskopf LA, Sokolow LZ, Olsen SJ, Bresee JS, Broder KR, Karron RA. Prevention and control of influenza with vaccines: recommendations of the Advisory Committee on Immunization Practices (ACIP) - United States, 2015-2016 influenza season. MMWR Morb Mortal Wkly Rep 2015;64:818-25.

3. CDC. Immunization of health-care personnel: recommendations of the Advisory Committee on Immunization Practices (ACIP). MMWR Recomm Rep 2011;60(No. RR-7). 


\section{Percentage* of Uninsured Persons Aged $<65$ Years With No Health Insurance Coverage Because of Cost, ${ }^{\dagger}$ by Race/Ethnicity ${ }^{\S}$ - National Health Interview Survey, " United States, 2004 and 2014}

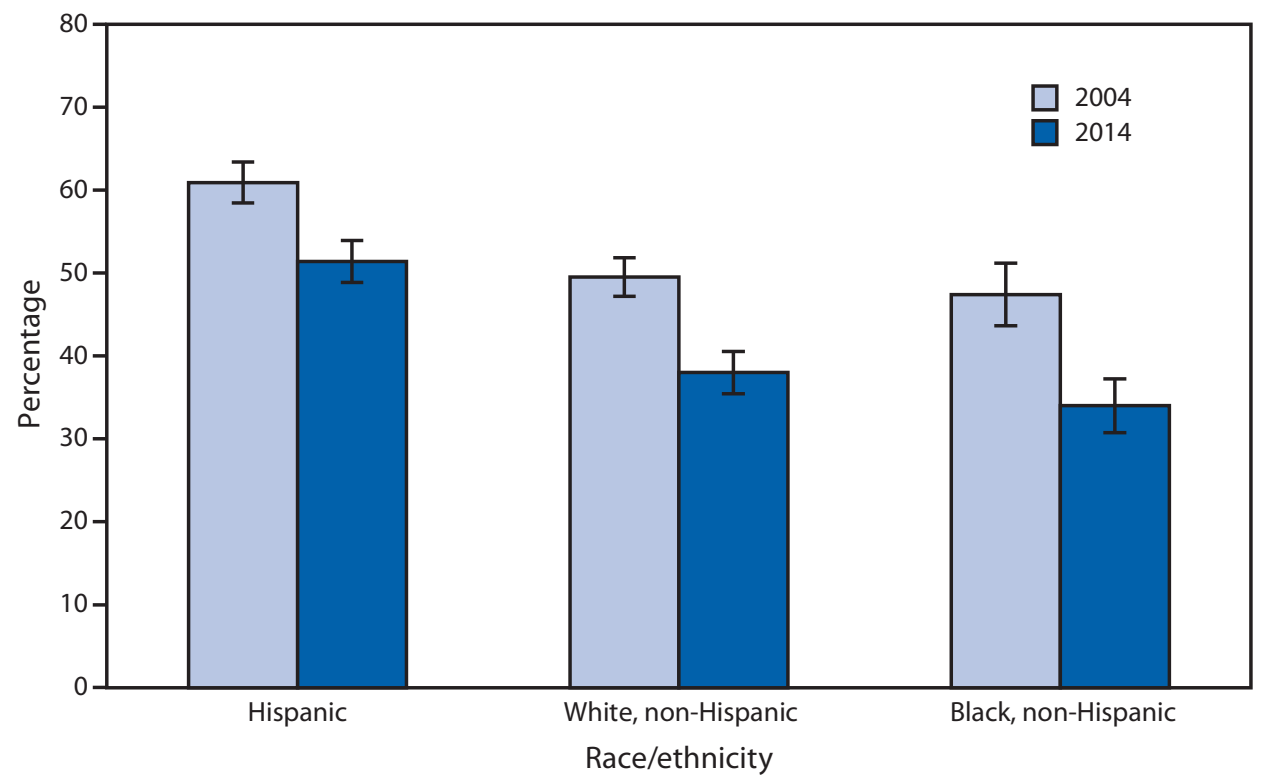

\footnotetext{
* With $95 \%$ confidence intervals.

† Based on the family respondent's response to a survey question that asked about uninsured family members, "Which of these are reasons (person) stopped being covered or does not have health insurance?" Reasons included lost job or change in employment, change in marital status or death of a parent, ineligible because of age or left school, employer didn't offer or insurance company refused, cost, Medicaid stopped, and other reason. More than one reason could be provided.

$\S$ Persons of Hispanic ethnicity might be of any race or combination of races.

I" Estimates are based on household interviews of a sample of the civilian, noninstitutionalized U.S. population and are derived from the National Health Interview Survey Family core component. Unknowns were excluded from the denominators when calculating percentages.
}

From 2004 to 2014, the percentage of uninsured persons aged <65 years for whom cost was a reason for not having health insurance coverage decreased from $60.9 \%$ to $51.4 \%$ among uninsured Hispanic persons, from $49.5 \%$ to $38.0 \%$ among non-Hispanic white persons, and from 47.4\% to 34.0\% among non-Hispanic black persons. In 2004 and 2014, uninsured Hispanic persons aged $<65$ years were more likely than uninsured non-Hispanic white and non-Hispanic black persons to lack health insurance coverage because of cost.

Sources: Adams PF, Barnes PM. Summary Health Statistics for the U.S. Population: National Health Interview Survey, 2004. Vital Health Stat 10(229) 2006. Available at http://www.cdc.gov/nchs/data/series/sr_10/sr10_229.pdf. National Health Interview Survey, 2014 data. Available at http://www.cdc.gov/nchs/nhis.htm.

Reported by: Patricia F. Adams; Michael E. Martinez, MPH, MHSA, bmd7@cdc.gov, 301-458-4758. 



The Morbidity and Mortality Weekly Report (MMWR) Series is prepared by the Centers for Disease Control and Prevention (CDC) and is available free of charge in electronic format. To receive an electronic copy each week, visit MMWR's free subscription page at http://www.cdc.gov/mmwr/mmwrsubscribe.html. Paper copy subscriptions are available through the Superintendent of Documents, U.S. Government Printing Office, Washington, DC 20402; telephone 202-512-1800.

Readers who have difficulty accessing this PDF file may access the HTML file at http://www.cdc.gov/mmwr/index2015.html. Address all inquiries about the MMWR Series, including material to be considered for publication, to Executive Editor, MMWR Series, Mailstop E-90, CDC, 1600 Clifton Rd., N.E., Atlanta, GA 30329-4027 or to mmwrq@cdc.gov.

All material in the MMWR Series is in the public domain and may be used and reprinted without permission; citation as to source, however, is appreciated. Use of trade names and commercial sources is for identification only and does not imply endorsement by the U.S. Department of Health and Human Services.

References to non-CDC sites on the Internet are provided as a service to $M M W R$ readers and do not constitute or imply endorsement of these organizations or their programs by CDC or the U.S. Department of Health and Human Services. CDC is not responsible for the content of these sites. URL addresses listed in $M M W R$ were current as of the date of publication.

ISSN: 0149-2195 (Print) 